\title{
Evaluation of complications according to the modified Clavien system adapted for percutaneous nephrolithotomy
}

\section{Perkütan nefrolitotomi için uyarlanmış modifiye Clavien sistemine göre komplikasyonlarımızın değerlendirilmesi}

\author{
Osman Murat İpek \\ Dr. Lütfi Kırdar Kartal Eğitim Ve Araştırma Hastanesi, Üroloji Kliniği, İstanbul, Türkiye
}

Dergiye Ulaşma Tarihi: 17.04.2018 Dergiye Kabul Tarihi:02.05.2018 Doi: 10.5505/aot.2018.21347

\begin{abstract}
ÖZET
GíRiş ve AMAÇ: 1980'lerden günümüze kullanılan ekipmanların teknolojisindeki gelişmelerle perkütan nefrolitotomiyle (PNL) taşsızlık oranlarında artış, operasyon süresinde kısalma, hastanede kalış süresinde azalma ile daha güvenilir ve etkin hale gelmiştir. Ancak peroperatif ve postoperatif komplikasyon oranları zaman içerisinde azalmış ancak kaybolmamıştır. PNL, minimal invaziv bir yöntem olarak açık taş cerrahisinin yerini almıştır. Bu çalışmamızda olgularda gelişen komplikasyonlar modifiye Clavien sistemine göre ve PNL için uyarlanmış modifiye Clavien sistemine göre inceleyip farklılıkları saptamayı amaçladık.

YÖNTEM ve GEREÇLER: Çalı̧̧maya Kasım 2004 ile Ocak 2013 tarihleri arasında kliniğimizde PNL operasyonu uygulanmış 928 hastadaki 980 renal üniteye uygulanan 1011 PNL operasyonu dahil edildi. Her ünite için preoperatif, operatif, postoperatif veriler retrospektif olarak değerlendirildi. Hastalarda gelişen komplikasyonlar modifiye Clavien sistemine göre ve PNL için uyarlanmış modifiye Clavien sistemine göre siniflandırıldi.

BULGULAR: Tüm vakalarda komplikasyon oran $\% 18.29$ olarak bulundu. Clavien derecelendirilmesine göre derece 1'de 23 komplikasyon (\%2.27), derece 2'de 143 komplikasyon (\%14.14), derece 3A'da 11 komplikasyon (\%1.08), derece 3B'de 6 komplikasyon (\%0.59), derece 4A'da 4 komplikasyon (\%0.39), derece 4B'de 15 komplikasyon (\%1.48) görülürken, derece 5'e uygun komplikasyon görülmemiştir. PNL için modifiye Clavien derecelendirilmesine göre derece 1'de 23 komplikasyon (\%2.27), derece 2'de 144 komplikasyon (\%14.24), derece 3A'da 22 komplikasyon (\%2.17), derece 3B'de 9 komplikasyon (\%0.89), derece 4A'da 4 komplikasyon (\% 0.39) görülürken, derece 4B ve 5'e uygun komplikasyon görülmemiştir.

TARTIŞMA ve SONUÇ: PNL'ye uyarlanmış modifiye Clavien sistemine göre sınıflandırmalarda düşük dereceli komplikasyonlarda fark saptanmazken; yüksek dereceli komplikasyonlarda düşüş gözlenmiştir. Bu nedenle PNL'ye uyarlanmış modifiye Clavien sistemine göre sınıflandırmanın daha objektif olduğunu düşünmekteyiz.
\end{abstract}

Anahtar Kelimeler: PNL, Komplikasyon, modifiye Clavien sistemi, Böbrek taş1

\section{ABSTRACT}

INTRODUCTION: Percutaneous nephrolithotomy (PNL) in technology today with the development of the equipment used from 1980, the stone-free rate increase, reduction in operation time, with a reduction in length of hospital stay has become more reliable and efficient. However, the perioperative and postoperative complication rates decreased over time but did not disappear. PNL has substituted of open stone surgery as a minimally invasive method. In this study, we aimed to determine the differences in the complications developed according to the modified Clavien system and the modified Clavien system adapted for PNL.

METHODS: The study included 1011 PNL operations performed in 980 renal units in 928 patients who underwent PNL operation between November 2004 and January 2013 in our clinic. Preoperative, operative and postoperative data were evaluated retrospectively for each unit. Complications developed in patients were classified according to the modified Clavien system and the modified Clavien system adapted for PNL. RESULTS: The complication rate was $\% 18.29$ in all cases. According to Clavien's classified, there were 23 
(\%2.27) complications in grade 1, $143(\% 14.14)$ complications in grade $2,11(\% 1.08)$ complications in grade 3A, $6(\% 0.59)$ complications in grade 3B, 4 (\%0.39) complications in grade 4A, 15 (\%1.48) complications in grade $4 \mathrm{~B}$ were seen, but no complication according to grade 5 was observed. According to the modified Clavien classified for PNL, 23 (\%2.27) complications in grade 1, 144 (\%14.24) complications in grade 2, 22 (\%2.17) complications in grade 3A, $9(\% 0.89)$ complications in grade 3B, There were $4(\% 0.39)$ complications in grade $4 \mathrm{~A}$, but no complications according to grade $4 \mathrm{~B}$ and 5 .

DISCUSSION AND CONCLUSION: Classification according to modified Clavien system adapted to PNL did not show any difference in low-grade complications; there was a decline in high-grade complications. Therefore, we think that classifying according to modified Clavien system adapted to PNL is more objective.

Keywords: PNL, Complication, modified Clavien system, renal stone

\section{GíRiș}

Böbreğe perkütan girişimin ilk olarak 1955 y1lında Goodwin tarafindan uygulanmaya başlanmasından sonra renal taşların tedavisi için perkütan cerrahi yöntemi Fernstrom ve Johansson tarafından 1976'da tarif edilmiştir $(1,2)$. 1980'lerden günümüze kullanılan ekipmanların teknolojisindeki gelişmelerle perkütan nefrolitotomide (PNL) taşsızlık oranlarında artış, operasyon süresinde kısalma, hastanede kalış süresinde azalma ile daha güvenilir ve etkin hale gelmiştir. Ancak peroperatif ve postoperatif komplikasyon oranları zaman içerisinde azalmış ancak kaybolmamıştır. PNL, minimal invaziv bir yöntem olarak açık taş cerrahisinin yerini almıştır.

PNL'nin en s1k karşıllaşılan komplikasyonları; ateş (\%21-32.1), kan transfüzyonu gerektiren kanama (\%11.2-17.5) ve ekstravazasyondur (\%7.2). Septisemi (\%0.3-4.7), kolon yaralanmas1 (\%0.2-4.8) ve plevral yaralanma (\%0-3.1) ise nadir karşılaşılan majör komplikasyonlardır. Çok sayıda PNL komplikasyonlarını değerlendiren çalışma olmasına rağmen standardize edilmemiştir. Uzun süredir cerrahi komplikasyonları standardize edip sinıflayan Clavien sistem kullanılmaktadır. 2004 yılında Clavien ve arkadaşları, 1992 yılında yaptıkları siniflandırmayı modifiye ettiklerini bildirmişlerdir. Buna göre derece 1 komplikasyonlar, farmakolojik, endoskopik veya cerrahi müdahaleye gerek duyulmayan postoperatif dönemdeki normal dış1 değişiklikleri kapsar. Derece 1'de kullanılabilen ilaçlar diüretikler, antiemetikler, antipiretikler, antiinflamatuarlar ve elektrolitlerdir. Derece 2 komplikasyonlar ise diğer medikal ilaçların kullanılmasını gerektiren durumlardır. Örneğin total parenteral nütrisyon (TPN) ürünleri, kan transfüzyonu veya diğer antihipertansif ilaçlar. Derece 3 komplikasyonlar ise artık cerrahi veya endoskopik müdahale gerektiren durumlar1 kapsar. Bunun ise 2 alt sinifi mevcuttur. 3A lokal anestezi altında müdahale edilen komplikasyonlarken, 3B ise genel anestezi altında müdahale edilen durumlardir. Derece 4 komplikasyonlar ise organ bozukluklarını kapsar. 4A tek organ bozukluğuyken, 4B ise çoklu organ bozukluğudur. Derece 5 ise hastanın kaybıdır (3). Clavien sisteminin geçerliği ve güvenirliği perkütan nefrolitotomi operasyonu için uyarlanmamıştır. CROES (The Clinical Research Office of the Endourological Society) PNL çalışma grubu perkütan nefrolitotomiye özgü komplikasyonları uluslararası anket ile 74 uzman üroloğun görüşleriyle Clavien derecelendirmesine göre yeniden sinifladı (4). $\mathrm{Bu}$ çalışmamızda olgularda gelişen komplikasyonlar modifiye Clavien sistemine göre ve PNL için uyarlanmış modifiye Clavien sistemine göre inceyip farklılıkları saptamayı amaçladık.

\section{GEREÇ ve YÖNTEM}

Çalışmaya Kasım 2004 ile Ocak 2013 tarihleri arasında kliniğimizde PNL operasyonu uygulanmış 1011 renal ünite dahil edildi. Her ünite için preoperatif [cinsiyet, yaş, vücut kitle indeksi(VKI), operasyon tarafi, daha önce taş nedeniyle yapılan işlemler, ektazi ve derecesi, 
taş lokalizasyonu, taş alanı ve hacmi], operatif (operasyon süresi, skopi süresi, giriş sayısı, giriş yapılan kaliks) ve postoperatif (hemoglobin, hemotokrit, komplikasyon, transfüzyon yapılması, taşsızlık, nefrostomi çekilme süresi, hastanede kalış süresi, ek girişim ihtiyac1) retrospektif olarak değerlendirildi. Yaşamı tehdit eden komplikasyonlar göz önüne alındı.

Kanama diatezi, tek böbrekli, aktif üriner enfeksiyonu, retrorenal kolon, renal tümörü olan hastalar çalışmaya alınmadı. Operasyon öncesi tüm hastalara bilgilendirilmiş onam formu imzalatıldı. Taş alanı, tüm abdomen spiral bilgisayarlı tomografi (BT) üzerinde taşın en uzun çapı ve bunu dik kesen çapın çarpılması ile $\mathrm{mm}^{2}$ cinsinden hesaplandi. Birden fazla taş olması durumunda her taş için ayrı ayrı hesaplanıp toplam taş yükü ölçüldü. Opak taşlar için operasyon sonrası çekilen direk üriner sistem grafisinde (DÜSG) $4 \mathrm{~mm}$ ve altı taşlar klinik olarak anlamsız fragmanlar (CIRF) olarak kabul edildi. Opak olmayan taşların değerlendirmesinde BT kullanıldı. Operasyon öncesi hazırlıkta tüm hastaların idrar kültürünü de içeren laboratuar analizleri ve radyolojik görüntüleme çalışmaları yapıldı. İdrar kültürlerinde üreme olan hastalar, antibiyogramdaki sonuçlara göre uygun antibiyotiklerle tedavi edilip idrarlarının steril olması sağland.

Genel anestezi indüksiyonu sağlandıktan sonra litotomi pozisyonu verilen hastalara toplayıcı sistemin boşluklarının opaklaşması ve genişlemesi için kontrast verilmesini sağlayacak olan $6 \mathrm{~F}$ açık uçlu üreter kateteri ipsilateral yerleştirilip foley katetere sabitlendi. Daha sonra hastalar, C kolluyla uyumlu masa üzerinde prone pozisyona alınarak floroskopik kontrol altında uygun kaliksin değişik planlarda $\mathrm{C}$ kolluyla görüntülenmesi yardımıyla perkütan girişim iğnesi (18G Percutaneous Access Needle, Boston Scientific Corporation, Natick MA) ile giriş yapıldı. Toplayıcı sisteme kılavuz telin
(Sensor Guide Wire, Boston Scientific) yerleştirilip tel üzerinden 14 F'e kadar yol dilate edildi. Dual lumen kateter (Dual Lumen Ureteral Access Catheter, Cook Medical) üzerinden ikinci bir k1lavuz tel güvenlik amacıyla yerleştirildi. Daha sonra balon dilatatör (NephroMax Microvasive High Pressure Balloon Catheter, Boston Scientific) veya Amplatz dilatatörlerle (Amplatz Renal Dilator Set, Cook Medical, IN, USA) 30 F'e kadar dilatasyon sağlandı. $30 \mathrm{~F}$ Amplatz kılıf içinden 26 F nefroskopla (Karl Storz GmbH, Tuttlingen, Germany) toplayıc1 sisteme girilip pnömotik, ultrasonik ya da her iki litotriptör (Swiss Lithoclast, EMS, Nyon, Switzerland) yardımıyla taşlar kırıldı ve kırılan parçalar da endoskopik kavrayıcılarla dışarı alındı. Operasyon sonrasında $14 \mathrm{~F}$ nefrostomi tüpü (Malecot Nephrostomy Catheter, Cook Medical) yerleştirilip cilde sabitlendikten sonra işleme son verildi.

\section{BULGULAR}

Çalışmaya 928 hastadaki 980 renal üniteye uygulanan 1011 PNL operasyonu dahil edildi. 928 hastanın 952'sine tek seansta tek taraflı, 28'ine aynı seansta çift taraflı, 31'ine de başka bir seansta tekrar PNL operasyonu olmak üzere toplam 1011 girişim uyguland1. 185 hastada 196 komplikasyon gelişti. Bu hastaların yaş ortalamas1 $41.87 \pm 15.68$ y1l $(5-81$ y1l); VKI ortalaması $26,86 \pm 6,21 \mathrm{~kg} \backslash \mathrm{m}^{2 ;}$ 75'i kadın ve 110 'u erkekti. Ortalama taş alanı 950,75 \pm 712,62 $\mathrm{mm}^{2}$ (median:707); taş hacmi 3899,03 $\pm 3351,91 \mathrm{~mm}^{3}$ (median: 2703); operasyon süresi 135,02 \pm 48,08 dak; hastanede kalış süresi 5,88 $\pm 4,34$ gün (median: 6gün); nefrostomi çıkarılma 4,11 $\pm 2,93$ gün (median: 4 gün) olarak saptandı. $89(\% 48,1)$ hasta taşsız olarak kabul edildi. Tüm vakalarda komplikasyon oran1 \%18.29 olarak bulundu. Operasyonlarda 153 (\%15.13) kanama, 3 (\%0.29) dissemine intravasküler koagülasyon (DİK), 1 (\%0.09) hemotoraks, 1 (\%0.09) akut böbrek yetmezliği (ABY), 2 (\%0.19) kolon 
yaralanmas1, 1 (\%0.09) jejunum yaralanmas1, 4 (\%0.39) toplayıc1 sistem perforasyonu, 12 (\%1.18) sepsis, 12 (\%1.18) postoperatif üriner enfeksiyon, 5 (\%0.49) 24 saatten uzun sslatma nedeniyle $\mathrm{dj}$ stent takılması, 1 (\%0.09) nefrektomi, 1 (\%0.09) lober pnömoni, 3 (\%0.29) üretropelvik bileşke darlığı saptandı (Tablo-1).

Çalışmamızda Clavien

derecelendirilmesine göre derece 1'de 23 komplikasyon (\%2.27), derece 2'de 143 komplikasyon (\%14.14), derece 3A'da 11 komplikasyon (\%1.08), derece 3B'de 6 komplikasyon (\%0.59), derece 4A'da 4 komplikasyon (\%0.39), derece 4B'de 15 komplikasyon (\%1.48) görülürken, derece 5'e uygun komplikasyon görülmemiştir. PNL için modifiye Clavien derecelendirilmesine göre derece 1'de 23 komplikasyon (\%2.27), derece 2'de 144 komplikasyon (\%14.24), derece $3 A^{\prime}$ da 22 komplikasyon (\%2.17), derece 3B'de 9 komplikasyon $(\% 0.89)$, derece $4 \mathrm{~A}^{\prime} \mathrm{da} 4$ komplikasyon (\%0.39) görülürken, derece 4B ve 5'e uygun komplikasyon görülmemiştir (Tablo-2, Tablo-3).

\section{TARTIŞMA}

Perkütan nefrolitotominin komplikasyonları sınıflanmamıştır ve çözüm yollarının nasıl olacağ1 konusunda da görüş birliği yoktur. Dindo modifiye Clavien sistemi, cerrahi dünyasında kalitenin değerlendirilmesi için 6336 hastada düzenlenerek kullanıma girmiştir (3). Clavien derecelendirilmesine göre PNL komplikasyonlarının sinıflandırılması 2007 y1lında 811 hasta sonucunun retrospektif incelemesi yapılmıştır. Vakaların \%29.2'sinde komplikasyon gelişmiş olup; bunların Clavien sistemi ile sinıflandırıldığında, derece 1'de \%4, derece 2'de $\% 16.3$, derece $3 A^{\prime}$ 'da $\% 6.6$, derece 3B'de $\% 2.8$, derece $4 A^{\prime}$ da $\% 1.1$, derece $4 \mathrm{~B}$ 'de $\% 0.3$, derece 5 'de $\% 0.1$ oranlarında komplikasyon izlenmiştir (5). 2011 yılında 5724 hastanın retrospektif incelenmesinde vakaların \%85.5'nin sorunsuz geçtiği belirtilmiş. Clavien sistemi ile sinıflandırıldığında, derece 1 'de $\% 11.1$, derece 2 'de $\% 5.3$, derece $3 A^{\prime} d a \% 2.3$, derece $3 B$ 'de $\% 1.3$, derece $4 A^{\prime}$ da $\% 0.3$, derece $4 B^{\prime}$ de $\% 0.2$, derece 5 'de $\% 0.03$ oranlarında komplikasyonla karşılaştırıldığı belirtilmiş (6).

Çalışmalar arasında komplikasyonların yorumlanmasından dolayı çok farklı sonuçlarla karşı karşıya kalınmaktadır. Bundan dolayı derecelendirme sistemini, PNL komplikasyonlarının bildirilmesini güvenilir ve standart hale getirmek için CROES (The Clinical Research Office of the Endourological Society) PNL çalışma grubundan 74 ürologla birlikte perkutan nefrolitotomiye özgü komplikasyonları uluslararası anket ile Clavien derecelendirmesine göre yeniden sınıflanmıştır. Katılımcıların 528 hastada gelişen komplikasyonları değerlendirilmesi sonucu majör komplikasyonlarda görüş birliği sağlanırken minör komplikasyonlarda güvenirliğin düşük olduğu belirtilmiştir (4). Daha az yoruma dayalı olan PNL için modifiye Clavien derecelendirilmesinde komplikasyonların derecelerinde azalma olduğu görülmüş, ancak minör komplikasyonlarda belirgin artış saptanmamıştır. Literatürdeki komplikasyon oranlarının farklılığının objektiflik yerine yorum kullanılmasından kaynaklanmaktadır.

153 kanama komplikasyonu gelişen hastanın 130 (\%66.32)'una kan transfüzyonu yapılmıştır. 3 ( $\%$ 0.29) hastada operasyon sonras1 nefrostomi kateterinin 24 saat klemplenmesine rağmen hemoglobin ve hematoktik değerlerinde ciddi düşüşe neden olan kanamadan dolay1 renal anjiografi yapılmıştır. 2 hastada lasere renal damar ve 1 hastada psödoanevrizma renal anjiografi sirasinda tespit edilip metalik koil ile selektif anjioembolizasyon uygulanmıştır. İşlem sonrası kanamada dramatik düzelme görülmüş ve işlemin tekrarına gerek kalmamıştır. Çalışma kanalının renal hilusa yakın geçmesi veya doğrudan posteriora gitmesi vasküler lezyon olasılığını arttırır. Yüksek basınçlı 
lasere bir arterin düşük basınçlı ven veya parankime akması arteriovenöz fistül veya psödoanevrizma oluşmasına yol açar. 2200 PNL operasyonu sonrasinda kontrol altına alınamayan kanaması olan 17 (\%0.8) hastada renal anjiografi embolizasyona ihtiyaç duyulmuştur. 15 hastanın kanaması anjioembolizasyon sonrası devam etmemesine rağmen 2 hastaya parsiyel nefrektomi uygulanmıştır. Kanamaya sebep olacak risk faktörü tanımlanamamasına rağmen PNL sonrasinda renal anjiografi ve embolizasyon gerektiren durumlar tanımlanmıştır. Bunlar operasyon sonrası erken dönemde ortaya çıkıp nefrostomi klemplenmesi veya balon tamponad ile kontrol edilemeyen kanamalar; operasyonda replase edilmesine rağmen sonrasında 2 . ve 7 . günler arasında 3-4 ünite kan transfüzyonu gerektiren kanamalar; operasyon sonras1 $>7$ günde devam eden kanamalar olarak belirtilmiştir (7). Srivastava ve ark. (8) ise vasküler komplikasyonların oluşması öngören en önemli faktörü taş boyutu olarak tanımlamıştır.

Kan transfüzyonu gerektiren kanama komplikasyonu geniş çalışma kanalı, çoklu çalışma kanalı, renal pelvis perforasyonu, operasyon öncesi düşük hemoglobin seviyesi ve kan kaybı ile ilişkilidir. Önceki yıllarda yapılan çalışmaların sonucunda PNL sırasında böbrekten kanamaya bağl1 \%1-12 oranında kan transfüzyonu gerekmekteydir (6,9-12). Geniş hasta popülasyonuna sahip yayınlarda transfüzyon oran $1<\% 2.5$ ve şok belirtilerinin görülebileceği ciddi kanamalar ise hastaların $<$ \%3'ünde görülmektedir (9,13-15). Bunun yanında PNL sirasinda olan kanama komplikasyonlarını inceleyen 1854 hastalık retrospektif çalışmada ise transfüzyon oranı $\% 12.3$ ve kanamanın kontrolü amaciyla hastaların \%1.5'e renal anjioembolizasyon uygulandığı belirtilmiştir (16). Böbrek vasküler yapıya sahip olduğundan kanama görülmesi kaçınılmazdır. Arteriyel kanamalar, yüksek hızlı, açık renkli ve işlemi sonlandırabilir düzeyde iken; venöz kanama, irrigasyonla operasyona izin verecek düzeydedir. PNL sırasında aşırı kanama geniş nefrostomi kateteri yerleştirilmesi, klemplenmesi, hidrasyon ve balon tamponadi yapılarak önlenebilir. Kanamaların çoğu venöz kaynaklı olduğundan bu şekilde kontrol altına alınabilir.

12. kosta üzerinden perkütan giriş yapıldığında plevra veya akciğer yaralanma riski \% 10 iken, 11. kosta üzerinde bu oran \% 35 'e çıkmaktadır. 12. kosta üzerinden giriş yapılmas1 gerekiyorsa plevrayı korumak amaciyla BT veya ultrason kontrolünde ekshalasyon sonrası renal giriş yapılması zor durumlarda uygulanabilmektedir. Plevraya giriş yapılması durumunda plevral boşluğa hava girişi veya irrigasyon sıvısının ekstravazasyonu önlenmeli; hidrotoraks ya da hemotoraks oluşması durumunda gögüs tüpü takılarak sualtı drenaj yapılmalıdır. Torakoskopi veya torakotomi çok nadiren gerekmektedir. Bu komplikasyonun olması alt kaliks girişi yapılıp fleksible nefroskop ya da operasyon sonrasinda ESWL (Ekstracorporeal Shock Wave Lithotrpsy) ile kombine tedavilerle önlenebilir (9, 17-19). Çalışmamızda 12. kosta üzerinden üst kaliks girişi surasında 1 (\% 0.09) hastada hemotoraks gelişti. Mousavi-Bahar ve ark.'nın 123 hastada yaptıkları 11-12. interkostal giriş sonrası pnömotoraks gelişmesi \% 2.4 iken iteratürde suprakostal girişlerdeki pnömotoraks ve hemotoraks oranları $\% \quad 0-15.3$ arasinda değişmektedir (20-22). Bizim komplikasyon oranımız düşük olarak görünse de interkostal giriş sayısının yetersiz olması karşılaştırmayı zorlaştırmaktadır.

Toplayic1 sistem perforasyonu dilatasyon sırasında, taş kırılması ve alınması sürecinde, iyatrojenik, litotriptörün enerjisinin etkisi ya da nefroskopun kendisi ile oluşabilir. İrrigasyon sivis1 bu alandan retroperitona, intravasküler veya plevral alana ekstravaze olabilir. Bunun önlenmesi amaciyla perforasyon tanımlandıktan sonra hızla drenajı sağlanmalıdır. Drenajın sağlanmaması 
durumunda ürinom, hidrotoraks ve sepsis gibi ciddi problemlere yol açabilir. Modifiye Clavien sistemine göre majör komplikasyonlar içinde yer alan toplayıcı sistem perforasyonu görülme oranı $\% 0.4-11.5$ arasında değişmektedir $(23,24)$. Bizim çalışmamızda ise toplayıc1 sistem perforasyonu $4(0,39)$ hasta gibi düşük orandayken geniş hasta sayısına sahip uluslararası çalışmada ise \%3.4 olarak belirtilmiştir (6).

Komşu organ yaralanması için ana risk faktörü, posterior aksiller hattın anteriorundan giriş ve 10. interkostal aralıktan giriş yapılması olarak tanımlanmıştır $(25,26)$. Hasta sayısı 1000 üzerinde olan çalışmalarda kolon, dalak, karaciğer perforasyonu \% 0-0.4 oranında nadir rastlanan komplikasyonlardır (6,27). Genellikle tanı koymak belirti ve bulguların değişkenliğinden dolayı zordur. İşlem sonrasında abse ve fistül şeklinde gelişebilir. Yapılan 5039 hastalık çalışmada kolon perforasyonu için risk faktörleri sol böbreğe PNL yapılması, atnalı böbrek (\% 5.9), distandü kolon, aşırı zayıflık ve hasta yaşının ileri olması olarak tanımlanmış ve bunların olmasının riski \% 1 arttıracağı belirtilmiştir $(28,29)$. Barsak cerrahisi geçirmiş hastada duodenum veya kolon yaralanma olasıllı̆ 1 arttığından dikkatli olunmalıdır. Ekstraperitoneal perforasyon gelişmesi durumunda gastrointestinal sistem üriner sistemden ayrılmalıdır. Bu yüzden kolona kateter yerleştirilip antibiyotik tedavisi uygulanabilir. Kolon yaralanması olan çoğu vakada konservatif tedavi başarılıyken intraperitoneal perforasyon olan vakalarda hemen açık cerrahi yapılmalıdır. Barsakların ultrasonla kontrolü ve risk faktörlerine sahip hastaların doğru seçilmesiyle kolona giriş riski azaltılabilir (9). Geç dönemde kolokutanöz fistül gelişmesi durumunda 3 ay süre ile kolostomi açılmalıdır. Çalışmamızda PNL yapilan $2 \quad(\% 0.19)$ hastamizda kolon yaralanmas1 ve $1(\% 0.09)$ hastamızda jejunum yaralanması gerçekleşti. 1 hasta konservatif yaklaşılarak tedavi edildi. Diğer hastalar opere edilip barsakta perfore alan primer onarılip kolostomi ve loop jejunostomi açıldı. Sepsis gelişen hastalarda antibiyoterapi sonrasında kür sağlandı. Takipleri süresince kolorenal veya kolokutanöz fistül gelişmedi.

Taşların kırılmasıyla bakterilerin salınımı ve nefrostomiden bakteri girişi PNL sonrası üriner sistem enfeksiyonu gelişmesinde temel unsurlardır (30). Enfekte üriner taşa sahip hastalarda operasyon sonrasında ateş anlamlı olarak daha fazla görülmektedir. PNL sonrasında hastaların \%10-35'inde sistemik inflamatuar yanıt gelişirken, az sayıda hastada sepsise ilerler. Böbrekte piyonefroz mevcutsa, PNL öncesinde böbreğin drenajının sağlanıp profilaktik antibiyotik başlanması zorunludur (9). Sepsis ise y1kıc1 morbitesinin yanı sıra \%25-50 mortaliteye neden olmaktadır (31). Perioperatif profilaksi yapılmasına rağmen PNL sonras1 \%0.4-3 oranında sepsis gelişebilmektedir (32,33). Hastaya operasyon öncesi tek doz ya da kısa süreli antibiyotik profilaksisi verilmesinin postoperatif enfeksiyon gelişmesi üzerinde etkisi saptanmamıştır $(34,35)$. Yapılan çalışmalarda operasyon sonrası ateş oluşumunda ana risk faktörleri toplam operasyon süresi ve irrigasyon sıvısının miktarı olarak belirtilmiştir (9,36). Toplayıcı sistemde düşük basınçta çalışmak ve operasyon süresinin 90 dakikanın altında bitirilmesi önem taşımaktadır (9). Çalışmamamızda PNL sonrasında 24 hastada (\%2.37) postoperatif üriner sistem enfeksiyonu görüldü. Kan/idrar kültür ve antibiyograma uygun olarak antibiyoterapi başland. Sonrasında bu hastaların $12(\% 1.18)$ hastada sepsis görülürken, sonrasında 1 (\%0.09) hastada sepsis nedeniyle DİC gelişti. Tedavi sonrası hastalarda başka komplikasyon saptanmadi. Hastaların operasyon süreleri operasyon sonrası üriner enfeksiyon gelişenlerde ortalama 123 dakika olurken sepsis gelişenlerde ortalama 156 dakika olması ise mevcut kriterin üzerinde olduğunu göstermektedir. 
Fazla komplikasyon görülmesinin başlıca sebepleri operasyonların tek cerrah tarafından yapılmaması, asistan eğitiminin olması, komplikasyon ihtimali yüksek hastaların hastanemize yönlendirilmesinden kaynaklanacağını düşünmekteyiz.

\section{SONUÇ}

PNL, minimal invaziv yaklaşım olarak kabul edilsede ölüme kadar oluşabilecek komplikasyon içermektedir. Komplikasyonların oluşumunda taş yükü, lokalizasyonu, cerrahın tecrübesi büyük rol oynasa da diğer faktörlerde gözardı edilmemelidir. Minimal invaziv cerrahi operasyonlarda ortaya çıkabilecek komplikasyonların standardizasyonu gerekmekte olup bu konuda kesin bir görüş birliği yoktur. PNL'e uyarlanmış modifiye Clavien sistemine göre sinıflandırmalarda düşük dereceli komplikasyonlarda fark saptanmazken; yüksek dereceli komplikasyonlarda düşüş gözlenmiştir. $\mathrm{Bu}$ nedenle PNL'ye uyarlanmış modifiye Clavien sistemine göre sinıflandırmanın daha objektif ve kullanıma uygun olduğunu düşünmekteyiz.

Tablo 1. Görülen komplikasyonlar

\begin{tabular}{|c|c|}
\hline KOMPLIKASYON & {$[\mathbf{n}(\%)]$} \\
\hline Kanama & $153(\% 15.13)$ \\
\hline Dissemine İntravasküler Koagülasyon & $3(\% 0.29)$ \\
\hline Hemotoraks & $1(\% 0.09)$ \\
\hline Akut Böbrek Yetmezliği & $1(\% 0.09)$ \\
\hline Kolon yaralanması & $2(\% 0.19)$ \\
\hline Jejunum yaralanması & $1(\% 0.09)$ \\
\hline Toplayıcı sistem perforasyonu & $4(\% 0.39)$ \\
\hline Sepsis & $12(\% 1.18)$ \\
\hline Postoperatif üriner enfeksiyon & $12(\% 1.18)$ \\
\hline 24 saatten uzun Islatma nedeniyle & $5(\% 0.49)$ \\
\hline Double J stent takılması & $1(\% 0.09)$ \\
\hline Nefrektomi & $1(\% 0.09)$ \\
\hline Lober Pnömoni & $3(\% 0.29)$ \\
\hline Ureteropelvik Bileşke Darlı̆̆ı
\end{tabular}


Tablo 2. PNL komplikasyonlarının Clavien ve PNL için modifiye Clavien sistemlerine göre derecelendirilmesi

\begin{tabular}{|c|c|c|}
\hline KOMPLİKASYON & $\begin{array}{c}\text { CLAVIEN } \\
\text { DERECELENDIRMESİ }\end{array}$ & $\begin{array}{l}\text { PNL İÇİN MODİFIYYE } \\
\text { CLAVIEN } \\
\text { DERECELENDIRMESI }\end{array}$ \\
\hline $\begin{array}{l}\text { Kan transfüzyonu yapılmayan kanama } \\
\text { (n: 23) }\end{array}$ & Derece 1 & Derece 1 \\
\hline $\begin{array}{l}\text { Kan transfüzyonu yapılan kanama } \\
\text { (n:130) }\end{array}$ & Derece 2 & Derece 2 \\
\hline $\begin{array}{l}\text { Anjioembolizasyon } \\
(\mathbf{n}: 3)\end{array}$ & Derece 3B & Derece 3B \\
\hline $\begin{array}{l}\text { Dissemine İntravasküler Koagülasyon } \\
(\mathbf{n}: 3)\end{array}$ & Derece 4B & Derece 4A \\
\hline $\begin{array}{l}\begin{array}{l}\text { Akut Böbrek Yetmezliği } \\
\text { (n:1) }\end{array} \\
\end{array}$ & Derece 3A & Derece 4A \\
\hline $\begin{array}{l}\text { Hematoraks } \\
(\mathrm{n}: 1)\end{array}$ & Derece 3A & Derece 3A \\
\hline \multirow{2}{*}{$\begin{array}{l}\text { Kolon yaralanması } \\
(\mathrm{n}: 2)\end{array}$} & \multirow{2}{*}{ Derece 4A } & Derece 2 (konservatif) \\
\hline & & Derece 3B (kolostomi) \\
\hline $\begin{array}{l}\text { Jejenum yaralanması } \\
(\mathbf{n}: 1)\end{array}$ & Derece 4A & Derece 3B \\
\hline $\begin{array}{l}\text { Toplayıcı sistem perforasyonu } \\
\text { (n:4) }\end{array}$ & Derece 3A & Derece 3A \\
\hline $\begin{array}{l}24 \text { saatten uzun islatma } \\
\text { nedeniyle Double J stent takılması } \\
\text { (n: 5) }\end{array}$ & Derece 3A & Derece $3 \mathrm{~A}$ \\
\hline $\begin{array}{l}\text { Postoperatif üriner enfeksiyon } \\
\text { (n:12) }\end{array}$ & Derece 2 & Derece 2 \\
\hline $\begin{array}{l}\text { Sepsis } \\
(\mathbf{n}: 12)\end{array}$ & Derece 4B & Derece 3A \\
\hline $\begin{array}{l}\text { Loberpnömoni } \\
(\mathbf{n}: 1)\end{array}$ & Derece 2 & Derece 2 \\
\hline $\begin{array}{l}\text { Nefrektomi } \\
(\mathrm{n}: 1)\end{array}$ & Derece 4A & Derece 3B \\
\hline $\begin{array}{l}\text { Ureteropelvik Bileşke Darlığı } \\
\text { (n: 3) }\end{array}$ & Derece 3B & Derece 3B \\
\hline
\end{tabular}


Tablo 3. Clavienve PNL için modifiye Clavien sistemi derecelendirilmesine göre komplikasyonların görülme sıklı̆̆1

\begin{tabular}{|c|c|c|c|}
\hline \multicolumn{2}{|c|}{ DERECE } & $\begin{array}{c}\text { CLAVİEN } \\
\text { DERECELENDİRMESI }\end{array}$ & $\begin{array}{l}\text { PNL İÇİN MODİFIYYE } \\
\text { CLAVIEN } \\
\text { DERECELENDİRMESI }\end{array}$ \\
\hline \multicolumn{2}{|c|}{1} & $23(\% 2.27)$ & $23(\% 2.27)$ \\
\hline \multicolumn{2}{|c|}{2} & $143(\%$ 14.14) & $144(\%$ 14.24) \\
\hline \multirow{2}{*}{3} & A & $11(\%$ 1.08) & $22(\% 2.17)$ \\
\hline & B & $6(\% \quad 0.59)$ & $9(\% \quad 0.89)$ \\
\hline \multirow{2}{*}{4} & $\mathbf{A}$ & $4(\% \quad 0.39)$ & $4(\% \quad 0.39)$ \\
\hline & B & $15(\% 1.48)$ & - \\
\hline \multicolumn{2}{|c|}{5} & - & - \\
\hline
\end{tabular}

\section{REFERENCES}

1. Goodwin WE, Casey W, Woolf W. Percutaneous trocar (needle) nephrostomy in hydronephrosis. J Am Med Assoc 1955. 157: 891-894.

2. Fernstrom I, Johanson B. Percutaneous pyelolithotomy. Scand J Urol Nephrol 1976. 10: 257-259.

3. Dindo D, Demartines N, Clavien PA. Classification of surgical complications: a new proposal with evaluation in a cohort of 6336 patients and results of a survey. Ann Surg 2004. 240: 205-13.

4. de la Rosette JJ, Opondo D, Daels FP, et al. Categorisation of complications and validation of the Clavien score for percutaneous nephrolithotomy. Eur Urol, 2012. 62:246-55.

5. Tefekli A, Karadağ MA, Tepeler $\mathrm{K}$, et al. Classification of percutaneous nephrolithotomy complications using the modified clavien grading system: looking for a standard. Eur Urol 2008. 53:184-90.

6. de la Rosette JJ, Assimos D, Desai M, et al. The Clinical Research Office of the Endourological Society Percutaneous Nephrolithotomy Global Study: indications, complications, and outcomes in 5803 patients. J Endourol 2011. 25:11-7.

7. Kessaris DN, Bellman GC, Pardalidis NP, et al. Management of hemorrhage after percutaneous renal surgery. J Urol 1995. 153:604-8.

8. Srivastava A, Singh KJ, Suri A, et al. Vascular complications after percutaneous nephrolithotomy: are there any predictive factors? Urology 2005. 66:38-40.

9. Michel MS, Trojan L, Rassweiler J. Complications in percutaneous nephrolithotomy. Eur Urol 2007. 51:899-906.

10. Wezel F, Mamoulakis C, Rioja J, et al. Two contemporary series of percutaneous tract dilation for percutaneous nephrolithotomy. J Endourol 2009. 23:1655-61.
11. Agrawal MS, Gupta A, Bansal S, et al. A randomized comparison of tubeless and standard percutaneous nephrolithotomy. J Endourol 2008. $22: 439-42$

12. Tefekli A, Altunrende F, Tepeler K, et al. Tubeless percutaneous nephrolithotomy in selected patients: a prospective randomized comparison. Int Urol Nephrol 2007. 39:57-63.

13. El-Assmy AM, Shoekir AA, Mohsen T, et al. Renal access by urologist or radiologist for percutaneous nephrolithotomy--is it still an issue? J Urol 2007. 178: 916-20.

14. Soucy F, Ko R, Duvdevani M, et al. Percutaneous nephrolithotomy for staghorn calculi: a single center's experience over 15 years. J Endourol 2009. 23:1669-73.

15. Ziaee SA, Karami H, Aminsharifi A, et al. Onestage tract dilation for percutaneous nephrolithotomy: is it justified? J Endourol 2007. 21:1415-20.

16. Srivastava A, Singh KJ, Suri A, et al. Vascular complications after percutaneous nephrolithotomy: are there any predictive factors? Urology 2005. 66: 38-40.

17. Liatsikos EN, Kapoor R, Lee B, et al. "Angular percutaneous renal access". Multiple tracts through a single incision for staghorn calculous treatment in a single session. Eur Urol 2005. 48:832-7.

18. Gupta R, Kumar A, Kapoor R, et al. Prospective evaluation of safety and efficacy of the supracostal approach for percutaneous nephrolithotomy. BJU Int 2002. 90:809-13.

19. Matlaga BR, Shah OD, Zagoria RJ, et al. Computerized tomography guided access for percutaneous nephrostolithotomy. J Urol 2003. 170:45-7. 
20. Lojanapiwat B, Prasopsuk S. Upper-pole access for percutaneous nephrolithotomy: comparison of supracostal and infracostal approaches. J Endourol 2006. 20:491-4.

21. Falahatkar S, Enshaei A, Afsharimoghaddam A, et al. Complete supine percutaneous nephrolithotomy with lung inflation avoids the need for a supracostal puncture. J Endourol 2010. 24:213-8.

22. Mousavi-Bahar SH, Mehrabi S, Moslemi MK. The safety and efficacy of PCNL with supracostal approach in the treatment of renal stones. Int Urol Nephrol 2011. 43:983-7.

23. Shin TS, Cho HJ, Hong SH, et al. Complications of Percutaneous Nephrolithotomy Classified by the Modified Clavien Grading System: A Single Center's Experience over 16 Years. Korean J Urol 2011. 52:769-75.

24. Shalaby MM, Abdalla MA, Aboul-Ella HA, et al. Single puncture percutaneous nephrolithomy for management of complex renal stones. BMC Res Notes 2009. 2:62.

25. El-Nahas AR, Mansour AM, Ellaithy R, et al. Case report: conservative treatment of liver injury during percutaneous nephrolithotomy. J Endourol 2008. 22:1649-52.

26. Shah HN, Hegde SS, Mahajan AP, et al. Splenic injury: rare complication of percutaneous nephrolithotomy: report of two cases with review of literature. J Endourol 2007. 21:919-22.

27. El-Assmy AM, Shokeir AA, El-Nahas AR, et al. Outcome of percutaneous nephrolithotomy: effect of body mass index. Eur Urol 2007. 52:199-204.

28. Wu P, Wang L, Wang K. Supine versus prone position in percutaneous nephrolithotomy for kidney calculi: a meta-analysis. Int Urol Nephrol 2011. 43:67-77.

29. El-Nahas AR, Shokeir AA, El-Assmy AM, et al. Colonic perforation during percutaneous nephrolithotomy: study of risk factors. Urology 2006. 67:937-41.

30. Mariappan P, Tolley DA. Endoscopic stone surgery: minimizing the risk of post-operative sepsis. Curr Opin Urol 2005. 15:101-5.

31. Angus DC, Linde-Zwirble WT, Lidicker J, et al. Epidemiology of severe sepsis in the United States: analysis of incidence, outcome, and associated costs of care. Crit Care Med 2001.29:1303-10.

32. O'Keeffe NK, Mortimer AJ, Sambrook PA, et al. Severe sepsis following percutaneous or endoscopic procedures for urinary tract stones. Br J Urol 1993. 72:277-83.

33. Rao PN, Dube DA, Weightman NC, et al. Prediction of septicemia following endourological manipulation for stones in the upper urinary tract. J Urol 1991. 146:955-60.

34. Gallucci $M$, Fortunato $P$, Schettini $M$, et al. Management of hemorrhage after percutaneous renal surgery. J Endourol 1998. 12:509-12.

35. Moslemi MK, Movahed SM, Heidari A, et al. Comparative evaluation of prophylactic single-dose intravenous antibiotic with postoperative antibiotics in elective urologic surgery. Ther Clin Risk Manag 2010. 6:551-6.

36. Dogan HS, Sahin A, Cetinkaya Y, et al. Antibiotic prophylaxis in percutaneous nephrolithotomy: prospective study in 81 patients. J Endourol 2002. 16:649-53. 